\title{
On the occasion of the decennial publication of ZDM Mathematics Education by Springer
}

\author{
Gabriele Kaiser $^{1,2}$
}

(c) FIZ Karlsruhe 2017

ZDM Mathematics Education has a distinguished lineage, reaching back to the origins of mathematics education as a discipline in the 1960s. First published in 1969 under the name Zentralblatt für Didaktik der Mathematik, abbreviated $Z D M$, the journal then highlighted important international events in mathematics education, with a largely German readership. In the year 2007 Springer started to publish the journal. The original abbreviation of the journal $Z D M$ was maintained, in order to refer to its origin. However, with the implementation of a new sub-title The International Journal on Mathematics Education, now changed to Mathematics Education, the opening to an international audience became clear, offering new opportunities, both in scope and reach. The core idea was to continue to publish focused thematic volumes on issues of central importance such as curricula, assessment, problem solving, and professional development. Authors and editors were to represent the best of mathematics education around the world, and the readership was intended to be equally broad.

We are now celebrating the 10th anniversary of $Z D M$ Mathematics Education. This anniversary provides an opportunity to look back, to give new readers an opportunity to sample articles from the journal's history, and to look forward to the next decade of progress in mathematics education.

With Springer entering the stage, an international editorial board was implemented, thus integrating international

Gabriele Kaiser

gabriele.kaiser@uni-hamburg.de

1 Faculty of Education, University of Hamburg, Von Melle-Park 8, 20146 Hamburg, Germany

2 Learning Sciences Institute, Australian Catholic University, Brisbane, Australia scholars with those who are German-speaking, including the continuing Editor-in-chief. The bimonthly frequency of publication was maintained, with six issues per year. However, in contrast to the previous publication form, the journal was published both in printed format and in a webbased online version, the latter offering access to a much broader international readership via the world-wide presence of Springer.

The structure of the journal, which had been developed during the decade before Springer began publishing ZDM, has not been changed. Thematically focused issues edited by invited guest-editors from all over the world give $Z D M$ Mathematics Education its specific characteristics. ZDM Mathematics Education continued to work on an invitation-only basis, which allowed the publishing of coherent issues describing the state-of-the-art of selected topics, and reflecting topical trends of the discussion on mathematics education by invited well-known scholars.

The themes of the issues were multifaceted. However, there were recurrent topics and these can be grouped around the following broader themes:

- Comparative studies, especially between East Asian and Western countries:

- Effective mathematics teaching in East and West

- Asia Pacific focus on mathematics classrooms

- Exemplary mathematics instruction in East Asia

- Curriculum research in China and the US

- Values in East Asian mathematics education

- Cross-national studies on teaching and learning mathematics

- Lesson study in mathematics: an international perspective. 
- Teacher education and teachers' professional development:

- Empirical research on mathematics teacher education

- Creating and using representations of mathematics teaching in teacher development

- Developing teachers' expertise

- Measuring teacher knowledge from a cross-national perspective

- Theoretical frameworks in research on and with teachers

- Re-sourcing teacher work and interaction

- Promoting professional development of didacticians and mathematics teachers

- Evidence-based continuous professional development

- Perception, interpretation and decision making.

- Psychological topics:

- Flexible/adaptive use of strategies and representations

- Metacognition research

- Cognitive neuroscience and mathematics learning

- Cognitive neuroscience and mathematics learningrevisited after 5 years

- Mathematical thinking and learning

- Beliefs and beyond

- Creativity in mathematics education

- New perspectives on learning and cognition

- Inhibitory control in mathematics education.

- New technology and New media:

- Usage of dynamic mathematics technologies

- Historical aspects of the use of technology and devices

- Handheld technology in mathematics classrooms

- Interoperable interactive geometry

- Online mathematics education.

- Mathematics-specific topics:

- Learning, teaching and using measurement

- Probability in reasoning about data and risk

- Teaching and learning of calculus

- From patterns to generalization: development of algebraic thinking

- Geometry in primary school

- Numeracy.

- Research on classroom activities:
- Problem solving around the world

- Didactical and epistemological perspectives on mathematical proof

- Interdisciplinarity in mathematics education

- Implementation of inquiry-based learning

- Visualization as epistemological learning tool

- Classroom-based interventions in mathematics education

- Scaffolding and dialogic teaching

- Textbook research in mathematics education

- Language and communication.

- General aspects on mathematics education

- Didactics of mathematics as a scientific disciplinein memoriam of Hans-Georg Steiner

- Turning points in the history of mathematics teaching

- New perspectives on gender

- Enacted mathematics curriculum

- Socio-economic influences on mathematical achievements

- New perspectives on the didactic triangle

- Survey of research on mathematics education

- Mathematical working spaces in schooling

- Assessment and understanding young children's mathematical minds.

- Methodological issues:

- Networking strategies for connecting theoretical approaches

- Enactivist methodology

- Design research with a focus on learning processes.

- Country-specific issues:

- An issue focused on Nordic research

- South American tapestry of trends

- An issue on Turkish research developments

- Features of Korean mathematics education.

In recent years, each issue published is comprised of about 12 original papers, and additionally one survey paper on the state-of-the-art on the topic of this issue, and one or two commentary papers. As a result of this format, about 80 manuscripts are published per year, covering around 1100 pages (in standard paper-size and two-column format). With the introduction of a survey paper on the stateof-the-art in 2014, ZDM aimed to give even more concisely an overview of the latest developments concerning the topic of the specific issue. Commentary papers, which were 
introduced a few years earlier, aimed to provoke a discussion on the theme of the issue, which could not always be achieved.

A further milestone of the development of $Z D M-T h e$ International Journal on Mathematics Education was the change of the subtitle in 2015 leading to the current title of the journal as ZDM Mathematics Education. The main reason behind this decision was the ambiguity of the original subtitle The International Journal on Mathematics Education, which led to diverse perceptions of the thrust of the journal, which was not helpful for shaping a clear identity for this publication. It was therefore an obvious consequence to choose a distinct sub-title complementing $Z D M$ and keeping the original roots. With the new name $Z D M$ Mathematics Education, we hope to accomplish the goal of an unambiguous title preserving the roots as Zentralblatt für Didaktik der Mathematik.

Furthermore, ZDM Mathematics Education is characterised by strong support with an editorial office and language editing for papers of non-native speakers of English. This strong support by Springer allowed the establishment of a journal with a broad range of themes and topics reaching readers not only in Europe or North America; in contrast ZDM Mathematics Education is widely accepted in many Asian countries, showing the high interest of many Asian scholars in mutual exchange and joint learning processes. The strong German roots of ZDM Mathematics Education are apparent in the high importance of subject-specific issues and subject-related analyses in many issues, reflecting the appreciation for and priority given to the subject mathematics and content-related reflections.

On the occasion of the decennial publication of ZDM Mathematics Education by Springer one specific paper from each year has been selected for temporary free access. The paper is in most cases one of the most quoted papers in a particular year with a high number of downloads, i.e., a paper which has attracted a considerable amount of attention in the scientific community. The following papers were selected, in each case displaying an excellent example of the body of research published in ZDM Mathematics Education in that year:

- 2007: Problem solving in the United States (Schoenfeld)

- 2008: Secondary mathematics teachers' pedagogical content knowledge and content knowledge (Krauss et al.)

- 2009: Flexible and adaptive usage of strategies and representations (Heinze et al.)

- 2010: Metacognition in mathematics education (Schneider and Artelt)

- 2011: Using video to teach future teachers (Santagata and Guarino)

- 2012: Students' articulation of uncertainty (Ben-Zvi et al.)

- 2013: Textbook research in mathematics education (Fan et al.)

- 2014: Poverty, inequality and mathematics performance (Graven)

- 2015: Scaling a technology-based innovation (ClarkWilson et al.)

- 2016: Teacher professional knowledge and classroom management (König and Kramer)

The issues of ZDM Mathematics Education contain many more examples of excellent research, and it is our ardent hope that the members of the mathematics educational community will avail themselves of this resource.

Gabriele Kaiser.

Editor-in-chief 